\title{
Measurements of the upper troposphere and lower stratosphere during tropical cyclones using the GPS radio occultation technique
}

\author{
Biondi, Riccardo; Neubert, Torsten; Syndergaard, Stig; Nielsen, Johannes
}

Published in:

Advances in Space Research

Link to article, DOI:

10.1016/j.asr.2010.05.031

Publication date:

2011

Document Version

Early version, also known as pre-print

Link back to DTU Orbit

Citation $(A P A)$ :

Biondi, R., Neubert, T., Syndergaard, S., \& Nielsen, J. (2011). Measurements of the upper troposphere and lower stratosphere during tropical cyclones using the GPS radio occultation technique. Advances in Space Research, 47(2), 348-355. https://doi.org/10.1016/j.asr.2010.05.031

\section{General rights}

Copyright and moral rights for the publications made accessible in the public portal are retained by the authors and/or other copyright owners and it is a condition of accessing publications that users recognise and abide by the legal requirements associated with these rights.

- Users may download and print one copy of any publication from the public portal for the purpose of private study or research.

- You may not further distribute the material or use it for any profit-making activity or commercial gain

- You may freely distribute the URL identifying the publication in the public portal 


\section{Accepted Manuscript}

Measurements of the Upper Troposphere and Lower Stratosphere during Tropical Cyclones using the GPS Radio Occultation Technique

Riccardo Biondi, Torsten Neubert, Stig Syndergaard, Johannes Nielsen

PII:

S0273-1177(10)00376-5

DOI:

10.1016/j.asr.2010.05.031

Reference:

JASR 10212

To appear in:

Advances in Space Research

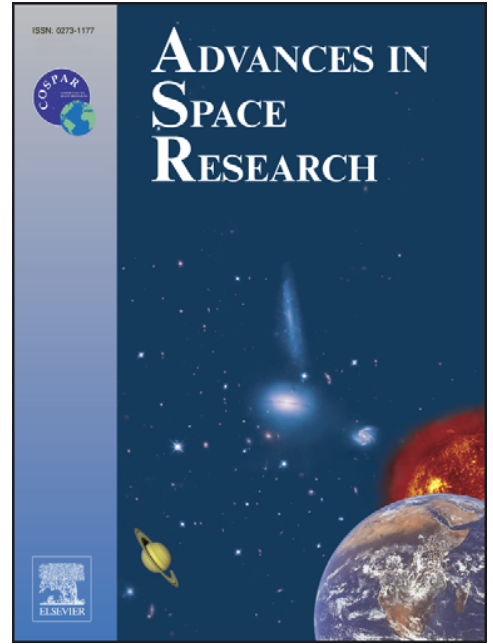

Received Date: $\quad 28$ January 2010

Revised Date: $\quad 28$ May 2010

Accepted Date: $\quad 31$ May 2010

Please cite this article as: Biondi, R., Neubert, T., Syndergaard, S., Nielsen, J., Measurements of the Upper Troposphere and Lower Stratosphere during Tropical Cyclones using the GPS Radio Occultation Technique, Advances in Space Research (2010), doi: 10.1016/j.asr.2010.05.031

This is a PDF file of an unedited manuscript that has been accepted for publication. As a service to our customers we are providing this early version of the manuscript. The manuscript will undergo copyediting, typesetting, and review of the resulting proof before it is published in its final form. Please note that during the production process errors may be discovered which could affect the content, and all legal disclaimers that apply to the journal pertain. 


\title{
Measurements of the Upper Troposphere and Lower Stratosphere during Tropical Cyclones using the GPS Radio Occultation Technique
}

\author{
Riccardo Biondi ${ }^{a}$, Torsten Neubert ${ }^{b}$, Stig Syndergaard ${ }^{c}$ Johannes Nielsen ${ }^{d}$ \\ ${ }^{a}$ DTU Space, National Space Institute, Juliane Maries Vej 30, 2100, Kфbenhavn $\emptyset$, \\ Denmark, ribi@space.dtu.dk \\ ${ }^{b}$ DTU Space, National Space Institute, Juliane Maries Vej 30, 2100, København Ø, \\ Denmark,neubert@space.dtu.dk \\ ${ }^{c}$ DMI, Danish Meteorological Institute, Lyngbyvej 100, 2100, Kфbenhavn Ø, Denmark, \\ ssy@dmi.dk \\ ${ }^{d}$ DMI, Danish Meteorological Institute, Lyngbyvej 100, 2100, Kobenhavn $\varnothing$, Denmark, \\ $j k n @ d m i . d k$
}

\begin{abstract}
Water vapour transport to the upper troposphere and lower stratosphere by deep convective storms affects the radiation balance of the atmosphere and has been proposed as an important component of climate change. The aim of the work presented here is to understand if the GPS radio occultation technique is useful for characterization of this process. Our assessment addresses the question if severe storms leave a significant signature in radio occultation profiles in the upper troposphere/lower stratosphere. Radio occultation data from the Constellation Observing System for Meteorology, Ionosphere and Climate (COSMIC) were analyzed, focusing on two particular tropical cyclones with completely different characteristics, the hurricane Bertha, which formed in the Atlantic Basin during July 2008 and reached a maximum intensity of Category 3, and the typhoon Hondo, which formed in the south Indian Ocean during 2008 reaching a maximum intensity of Category 4. The result is positive, suggesting that the bending angle of a GPS radio occultation signal contains interesting information on the atmosphere around the tropopause, but not any information regarding the water vapor. The maximum percentage anomaly of bending angle between $14 \mathrm{~km}$ and $18 \mathrm{~km}$ of altitude during tropical cyclones is typically larger than the annual mean by $5-15 \%$ and it can reach $20 \%$ for extreme cases. The results are discussed in connection to the GPS radio occultation receiver which will be part of the Atomic Clock Ensemble in Space (ACES) payload on the International Space Station.

\section{Introduction}

The International Space Station (ISS) is an interesting platform for observations of deep convective storms because the orbit inclination of $51.6^{\circ}$ allows instruments to monitor the major convective storm regions of the earth. An advanced GPS receiver is planned for the ISS as part of the Atomic Clock Ensemble in Space (ACES), payload (Svehla et al., 2006) and a number of optical cameras for the Atmosphere Space Interactions Monitor (ASIM) payload (Neubert et al., 2009). Both payloads will be mounted on the external platforms of the ESA (European Space Agency) Columbus laboratory module and be viewing primarily towards the limb in the forward direction. With these instruments the
\end{abstract}


ISS may potentially secure a unique data set on tropopause processes. It will also contribute to increase the number of occultation measurements in the tropical regions since the data distribution of the on-going GPS radio occultation (RO) missions is denser at mid and high latitudes due to the inclination of the orbits (Fig.1, Fig.2).

The water vapour content in the Earth's upper troposphere/lower stratosphere (UT/LS) is an important climate parameter (Manabe and Wetherald, 1967; Soden and Fu, 1995; Forster and Shine, 1999; SPARC, 2000; Solomon et al., 2010). Like $\mathrm{CO}_{2}$, stratospheric water vapour acts like a greenhouse gas, contributing to global warming of the atmosphere. Despite its relative diluteness, changes in stratospheric water vapour mixing ratio since 1960 could have accounted for up to $40 \%$ of the radiative forcing due to wellmixed greenhouse gases (Forster and Shine, 2002), however the contribution on global scale to the stratospheric water budget from deep convective processes is currently debated (Scherer et al., 2008; Fueglistaler et al., 2009). To gain a better understanding of deep convective processes, the study of Tropical Cyclones (TCs) could play an important role since they lead to deep convective activity. Although they are not frequent, they are larger than other tropical convective systems, exist for longer time and persist in the same areas for many hours or days with vigorous convective towers. The overshooting clouds in the tropics are usually outside of TCs, but there are some areas where overshoots are mostly due to TCs. In general they account for only $7 \%$ of the deep convection in the tropics but they contribute $15 \%$ of the convection that overshoot the tropopause (Romps and Kuang, 2009). Such TCs increase the water vapour content of the UT (Ray and Rosenlof., 2007) and they warm the mid troposphere and they cool the tropopause layers (Bath et al., 2002; Sherwood et al., 2003; Kim, 2005).

The GPS radio occultation (RO) technique (Kursinski et al., 1997) is useful for studying severe weather phenomena because the GPS signals penetrate through clouds and allow measurements of atmospheric profiles related to temperature, pressure, and water vapour with high vertical resolution. We have analyzed GPS RO profiles during severe storms to find out whether they provide significant information on the convection in the UT/LS. The storm systems studied are TCs which are known to reach high altitudes and may have a relatively large horizontal extent. GPS data from RO experiments onboard the Global Positioning System/Meteorology (GPS/MET) satellite (Rocken et al., 1997), the CHAllenging Minisatellite Payload (CHAMP) satellite (Wickert et al., 2001), the Satellite de Aplicaciones Cientificas-C (SAC-C) satellite (Hajj et al., 2004), and the Constellation Observing System for Meteorology, Ionosphere and Climate (COSMIC) six-satellite constellation (Anthes et al., 2008) were analyzed in relation to TC positions for the period 1996-2008, identifying several hundred ROs that coincide with TC positions. Whereas no evident variation at the tropopause is seen in the COSMIC Data Analysis and Archive Center (CDAAC) products such as water vapour, and pressure profiles, the GPS signal refractive index profile, the temperature profile and especially the bending angle profile, show a TC signature in the upper troposphere. The work presented here is focused on two particular TCs, the hurricane Bertha, which formed in the Atlantic Basin during July 2008 and reached a maximum intensity of Category 3 and typhoon Hondo, which formed in the south Indian Ocean in February 2008 and reaching the maximum intensity of Category 4. Using measurements from a variety of earth observation satellites and from aircraft, together with the best track information provided 
by the US National Hurricane Center (NHC), we reconstructed the characteristics of the two TCs and compared them to ROs from the COSMIC mission. The RO profiles were selected in a time window dependent on the TC advection velocity and a space window dependent on the TC radius and eye radius. The profiles of the selected ROs were then compared to those of an undisturbed atmosphere in the same region and during the same month. Finally statistical properties of all the TCs during 2008 are reported.

\section{Data description}

The tropical cyclones best tracks were collected from different sources: US National Hurricane Center (Atlantic, Caribbean, Gulf of Mexico and Eastern Pacific), Australian Government Bureau of Meteorology (Western, Northern, Eastern Australia), Japan Meteorological Agency (Western, Northern Pacific), Meteo France (Southwest Indian Basin) and Unysis Weather (North Indian Ocean Basin, Bay of Bengal and Arabian Sea). These sources usually provide information every 6 hours, including at least the name, coordinates, dates, pressure, maximum wind speed and category of the tropical cyclone. In some cases additional information is available, such as eye dimension (from Hurricane Hunters missions), moving cyclone direction, and speed.

The GPS/MET, CHAMP, SAC-C, and COSMIC GPS Radio Occultations that we have analyzed were downloaded from the CDAAC website. For the analysis of TCs we first selected the ROs within $400 \mathrm{~km}$ from the TC eye and within a time window of 3 hours. In this paper we present results from the COSMIC level2 products:

- atmPrf: containing so-called dry pressure and temperature (derived assuming no water vapour (Rocken et al., 1997), refractivity, bending angle, and impact parameter versus geometric height above mean sea level

- wetPrf: containing pressure, temperature and moisture (derived via a one-dimensional variational approach using ECMWF low resolution analysis data) interpolated to 100 meter height levels

- ecmPrf: containing pressure, temperature and moisture profiles generated from the ECMWF gridded analysis and co-located with occultation profiles.

To monitor the TC dimensions and the eye radius, we also used data from the Moderate Resolution Imaging Spectroradiometer (MODIS) onboard of the AQUA satellite as well as data from the Geostationary Operational Environmental Satellite (GOES).

\section{Case study: Bertha 2008}

Hurricane Bertha formed at the beginning of July 2008 near the West African coast and it became an extra tropical cyclone on $20^{\text {th }}$ of July. During its life, Bertha moved westward and increased in strength from tropical storm to hurricane category 3 in four days, maintaining hurricane status for several days. The track of Bertha is shown in Fig. 3.

For different reasons Bertha was our best choice. First of all, Bertha's track was long in time and space, increasing the probability to find ROs suitable for our studies. Eight COSMIC occultations were found close enough to hurricane Bertha in space and time. Moreover the long period in TC condition, allowed us to compare possible differences with tropical storm condition. Last but not least, in the same area there was not any other 
TC for a long time (the previous one was in 2007 and the next one two months later) so the upper tropospheric variations in that area were probably only due to hurricane Bertha. We used US NHC best track database as reference, providing date, time, coordinates, pressure and wind speed every 6 hours. We added information on the cyclone diameter using MODIS and GOES data, on the cyclone eye dimension using Hurricane Hunters dataset, and finally we computed the moving speed.

Only the ROs within the radius of the TC and the radius of the eye (when available) in a time window of 3 hours, were analyzed. Table 1 shows the times of the RO events.

\section{Case study: Hondo 2008}

Typhoon Hondo formed at the beginning of February 2008 in the mid Indian Ocean, it moved southward becoming TC category 4 in five days and maintaining TC status for a few days. It became tropical storm and tropical depression until the end of the month moving westward to Ile de La Reunion. The track of Hondo is shown in Fig. 4.

Some of the reasons for this choice were the same as for Bertha: the track was long in time and space, increasing the probability to find ROs suitable for our studies, seven COSMIC occultations were found close enough to Hondo in space and time and in the same area there were not any other TCs for a long time. But we also choose Hondo because its characteristics were completely different from Bertha's. During Bertha all the ROs analysed were in TC status, during Hondo they are mostly during tropical depression status. We used Meteo France best track database as reference, providing date, time, coordinates, pressure and wind speed every 6 hours. We added information on the cyclone diameter using MODIS and GOES data and we computed the moving speed.

Only the ROs within the radius of the TC in a time window of 3 hours were analyzed. Table 2 shows the times of Hondo's RO events.

\section{Profiles analysis}

The GPS receiver on COSMIC measures the phase and amplitude of two L-band signals. The bending angle is calculated from the phase and amplitude and refractivity is computed using Abel inversion. Details of the RO processing at CDAAC can be found in (Kuo et al., 2004). Temperature, pressure and water vapour is derived via a onedimensional variational (1Dvar) approach involving the refractivity and the ECMWF model. The particular implementation of the 1Dvar at CDAAC weights the refractivity observation much more than the model, giving a solution in which the temperature ( $T$ in Kelvin), pressure ( $p$ in $\mathrm{mb}$ ), and water vapour pressure ( $e$ in $\mathrm{mb}$ ) are basically consistent with the derived refractivity, $N$, according to

$$
N=77.6 \frac{p}{T}+3.73 \cdot 10^{5} \frac{e}{T^{2}}
$$


We first analyzed pressure, and water vapour profiles above the TC, focusing the attention on the upper troposphere, but we did not find any evident signature. Analysis of bending angle profiles however, provided interesting information.

Shown in Fig. 5 is an example of bending angle signature during Hurricane Bertha. The parameter plotted here is the bending angle percentage anomaly with respect to the annual mean value $\left(\alpha_{\mathrm{TC}}-\alpha_{\mathrm{Annual}}\right) / \alpha_{\mathrm{Annual}}$, where $\alpha_{\mathrm{TC}}$ is the bending angle value during the TC and $\alpha_{\text {Annual }}$ is the annual average bending angle exactly in the same area covered by the cyclone. To get the annual average we collected all the ROs of 2008 within the diameter of the TC. Considering the size of Bertha and Hondo, any annual mean is the average result of more than 160 ROs. In the same figure we show the TC season mean anomaly (May-October for this area) and the non-TC season mean anomaly (NovemberApril).

In the UT, between 14 and $18 \mathrm{~km}$, the bending angle anomaly increases during the TC season and this variation is generally larger during the hurricane. The RO profile was acquired from COSMIC the 8th of July 2008 at 2:01 UTC, at the time when Bertha was a major hurricane (Cat. 3) slowly moving to the north-west (less than $10 \mathrm{~km}$ per hour). The cyclone diameter was about $400 \mathrm{~km}$, the eye diameter $30 \mathrm{~km}$ and the mean location of the $\mathrm{RO}$ as provided by CDAAC was $117 \mathrm{~km}$ from the center.

The comparison of the bending angle anomaly during TC status with the bending angle anomaly during non-TC status in the same area shows how the presence of the TC influences this parameter, in fact that the positive anomaly in the UT/LS is not present in any case except during the cyclone (not shown).

All the eight cases that we have analyzed during Bertha, presented the same bending angle anomaly behavior, i.e., a large increase in the lower troposphere (between 4 and 8 $\mathrm{km}$ ), a decrease around $10 \mathrm{~km}$, and again an increase usually between 14 and $18 \mathrm{~km}$ (in all cases reaching more than $10 \%$ at the peak). The bending angle variation with the same tendency is also evident during July (not shown) although not as large.

In Fig. 6 and Fig. 7 we averaged the percentage anomalies for bending angle, refractivity, temperature, and water vapour mixing ratio (from COSMIC products and co-located ECMWF) of all eight ROs during Bertha. The refractivity anomaly is similar to the bending angle anomaly, although it is smaller and more smooth, and shifted slightly in altitude. This can be explained by the fact that the bending angle depends on the refractivity vertical gradients via an Abel integral transform (Kursinski et al., 1997). The temperature anomaly in the UT is somewhat symmetric to refractivity, which follows from eq. (1) and the fact that the first term on the right-hand-side dominates at these altitudes $(\Delta N / N \approx \Delta P / P-\Delta T / T)$, and indicates that the pressure anomaly is almost constant in altitude.. The water vapour mixing ratio anomaly is positive throughout the troposphere. Comparing these profiles with the co-located ECMWF profiles, it is evident that the model influences the derived mixing ratio profiles in the UT/LS to a large degree. The tendency of the mixing ratio is always determined by the model, but the 1Dvarderived mixing ratio usually has more variation than the ECMWF model. 
Although the results presented here contain interesting information about the vertical structure of the atmosphere inside hurricanes from the surface and up, the focus of this study is the positive bending angle anomaly in the UT/LS between 14 and $18 \mathrm{~km}$. Figure 8 shows the averaged bending angle anomaly in Fig. 6 and Fig. 7 above $12 \mathrm{~km}$. Also indicated in this figure is the standard deviation of the average, which shows that the average bending angle anomaly is statistically significant. Since the bending angle peaks at slightly different altitudes for the eight different cases, the maximum average anomaly is about $5 \%$, whereas the maximum anomalies in the individual profiles, as mentioned above, are larger.

Finally, the temperature profiles (Fig. 9) show the TCs warm core and a cold peak reached in the UT/LS. As can be seen from Fig. 9, the temperature is warmer than the annual average up to $13 \mathrm{~km}$, but above this altitude it becomes colder for a few kilometers and then again warmer. This tendency is consistent with previous studies (Knaff et al., 2000; Kidder et al., 2000; Cairo et al., 2008; Singh, 2008).

The temperature anomaly profile in Fig. 7 shows the opposite tendency and variation compared to the bending angle anomaly profile, and in principle it should be possible to identify TCs just by looking at the temperature anomalies. However, it is more difficult, in an automated way, to find a threshold to detect the temperature anomalies in the $\mathrm{UT/LS}$ than it is to find one to detect the bending angle anomalies.

Analysis of Hondo profiles in TC status, confirms the same pattern as we have found for Bertha. The bending angle anomaly during TC season and non TC season are clearly separated in the UT/LS and the signature in TC status is evident (not shown), the refractivity anomaly has a similar tendency and the temperature anomaly has opposite tendency compared to the bending angle (Fig. 10). During Bertha all the ROs analyzed were in TC status, during Hondo they occurred mostly during tropical depression status (Fig. 4). During tropical depression status the anomaly is usually smaller in amplitude between 14 and $18 \mathrm{~km}$ of altitude but the positive anomaly in this region is extended to higher altitudes (Fig. 11). This is reflected in the temperature profiles, which are warmer than the annual average up to $12 \mathrm{~km}$, but then it usually becomes colder for many kilometers and the difference to the annual average is larger as shown in Fig. 12.

\section{Statistics}

Using all the COSMIC GPS ROs of 2008, we have created a grid with one-degree resolution containing the annual averaged bending angle profiles. Any annual mean profile is the average result of about 50 ROs (depending on the latitude) acquired during the year. Comparing all the COSMIC ROs with the TCs tracks, we have found 104 coincidences (67 in the northern hemisphere and 37 in the southern hemisphere) with a time window of 3 hours and space distance of $400 \mathrm{~km}$ between TC center and ROs mean tangent point coordinates. Twentytwo of them were acquired during TCs, 48 during tropical storms, 6 during extra-tropical cyclones (about 30 degrees $\mathrm{N}$ ) and 28 during tropical depressions. About $97 \%$ of the cases presented a bending angle anomaly 
signature between 14 and $18 \mathrm{~km}$ of altitude (100\% of TCs). TCs and tropical depressions mostly present maximum bending angle anomalies less than $10 \%$ (just in a few cases it is larger), whereas tropical storms usually present positive anomalies between $10 \%$ and $20 \%$ (in a few cases also larger).

Fig. 13 shows the averaged bending angle anomaly (together with the standard deviation of the mean) for all 104 cases along TC tracks in 2008. The bending angle signature in the UT/LS is clear, confirming the same behavior that we have found during Bertha and Hondo.

A histogram of the anomaly maximum amplitude between 14 and $18 \mathrm{~km}$ is shown in Fig. 14 , revealing that the majority of the events present maximum anomaly between $5 \%$ and $15 \%$ with respect to the annual mean value. In a few cases the anomaly is negative. In these cases we do not have any information regarding the size of the TC and the analyzed ROs are more than $300 \mathrm{~km}$ away from the center. Thus, so we suppose that these outliers were not inside the cyclones.

\section{Discussion and conclusions}

Our results suggest that the bending angle of a GPS radio occultation signal contains interesting information on the atmosphere around the tropopause above tropical cyclones. Refractivity profiles from the COSMIC mission often show a variation at the same altitudes as the bending angle, but the signature is less pronounced. The water vapour anomalies from COSMIC agree largely with those of ECMWF, which can be explained by the fact that the ECMWF model is used in the derivation of the water vapour profiles. From our analysis of the saturation water vapour profile (not shown), such large variations of bending angle at the tropopause altitude cannot be due to the water vapour. However, the temperature profiles in the UT/LS are influenced from the presence of the convective system, cooling down the tropopause and creating sometimes variations of a few degrees. The reason for the observed positive bending angle anomaly during convective events is still under investigation.

In this initial study we conclude that GPS RO measurements, if taken from the International Space Station (ISS), would complement the current GPS RO missions by providing acquisitions in the tropical regions, where the density of profiles is the lowest. Supported by simultaneous observations of cloud structure by optical cameras, ROs from the ISS may then help address questions related to overshoot of clouds across the tropopause into the lower stratosphere.

\section{Acknowledgements}

We would like to thank G. Beyerle for the ACES simulator. Fig. 3 and Fig. 4 were made on the basis of images from Google Earth.

\section{References}


SPARC assessment of upper tropospheric and stratospheric water vapour. WCRP 113, WMO/TD No. 1043, SPARC report No. 2, 2000

Anthes, R.A., Bernhardt, P.A., Chen, Y. et al., The COSMIC/Formosat/3 mission: Early results. Bull. Amer. Meteor. Soc., 89, 313-333, 2008

Bath, G.S., Chakraborty, A., Nanjundiah, R.S. et al., Vertical thermal structure of the atmosphere during active and weak phases of convection over north Bay of Bengal: observation and model results. Curr. Sci. India, 83, 296-302, 2002

Cairo, F., Buontempo, C., MacKenzie, A.R. et al., Morphology of the tropopause layer and lower stratosphere above a tropical cyclone: a case study on cyclone Davina (1999). Atmos. Chem. Phys. 8, 3411-3426, 2008

Forster P.M., Shine, K.P., Stratospheric water vapour changes as a possible contributor to observed stratospheric cooling. Geophys. Res. Lett. 26, 3309-3312, 1999

Forster, P. M., Shine, K. P., Assessing the climate climate impact of trends in stratospheric water vapor. Geophys. Res. Lett., 29, 101-102, 2002

Fueglistaler, S., Dessler, A.E., Dunkerton, T.J., et al., Tropical tropopause layer. Rev. Geophys., 47, RG1004, DOI:10.1029/2008RG000267, 2009

Hajj, G.A., Ao, C.O., Iijima, B.A. et al., CHAMP and SAC-C atmospheric occultation results and intercomparisons. J. Geophys. Res., 109, D06109, doi:10.1029/2003JD003909, 2004

Kidder, S.Q., Goldberg, M.D., Zehr, R.M. et al., Tropical cyclone analysis using AMSU data. 10th Conference on Satellite Meteorology and Oceanography, 2000

Kim, H.C., The effect of deep convection on temperatures in the tropical tropopause layer and its implications to the regulation of tropical lower stratospheric humidity. $\mathrm{PhD}$ Thesis, University of Houston, USA, 2005

Knaff, J.A., Zehr, R.M., Goldberg, M.D. et al.,. An example of temperature structure differences in tow cyclone systems derived from the Advanced Microwave Sounder Unit. Wea. Forecasting, 15, 476-483, 2000

Kuo, Y.H., Wee, T.K., Sokolovskiy, S. et al., Inversion and error analysis of GPS radio occultation data. J. Meteor. Soc. Japan, 82, 507-531, 2004

Kursinski, E.R., Hajj, G.A., Schofield, J.T. et al., Observing Earth's atmosphere with radio occultation measurements using the Global Positioning System. J. Geophys. Res., 102, 23429-23465, 1997

Manabe S., Wetherald, R.T., Thermal equilibrium of the atmosphere with a given distribution of relative humidity. J. Atmos. Sci., 24, 241-259,1967

Neubert, T., Crosby, B., Huang, T.Y. et al., ASIM - an Instrument Suite for the International Space Station. AIP Conference Proceedings, pp: 8-12, DOI: 10.1063/1.3137718, 2009

Ray, E.A., Rosenlof, K.H., Hydration of the upper troposphere by tropical cyclones. J. Geophys. Res., 112, D12311, 2007 
Fig. 1 Histogram of the total number of COSMIC Radio Occultations during 2008 vs Latitude (between -50 and 50 degrees)

Fig . 2 Histogram of one month (July) simulated ACES Radio Occultations vs Latitude (between -50 and 50 degrees)

Fig. 3 Bertha's track. Green is tropical depression status, yellow is tropical storm, red is tropical cyclone, magenta is tropical cyclone maximum strength and cyan is the tangent points of radio occultation. Bertha started as tropical depression on the $3^{\text {rd }}$ of July, it became tropical storm the day after and it started to be TC on the $7^{\text {th }}$ of July reaching the maximum strength the $8^{\text {th }}$ of July. Until the $13^{\text {th }}$ it was in TC status.

Fig. 4 Hondo's track. Green is tropical depression status, yellow is tropical storm, red is tropical cyclone, magenta is tropical cyclone maximum strength and cyan is the tangent points of radio occultation. Hondo started as tropical depression on the $2^{\text {nd }}$ of February, it became TC the $5^{\text {th }}$ of February reaching the maximum strength the day after and it maintained the TC status until the $12^{\text {th }}$ of February when it quickly weakened to tropical depression. From the $14^{\text {th }}$ until the $29^{\text {th }}$ Hondo was almost al the time in tropical depression status. 
Fig. 5 Percentage anomaly of bending angle during Bertha (bold black line) compared with the averaged bending angle anomaly during TC season (dashed line), May-October in this region, and with the averaged bending angle anomaly during non TC season (grey line).

Fig. 6 Averaged anomaly profiles for the 8 cases during Bertha. Bending angle (bold black line), water vapor mixing ratio from COSMIC (dashed line) and water vapor mixing ratio from ECMWF (grey line)

Fig. 7 Averaged anomaly profiles for the 8 cases during Bertha. Bending angle (bold black line), refractivity (grey line), temperature from COSMIC (dashed line) and temperature from ECMWF (thin black line).

Fig. 8 Averaged bending angle anomaly profile for the 8 cases during Bertha (black line) above $12 \mathrm{~km}+/$ - the standard deviation of the mean (grey lines).

Fig. 9 Averaged temperature profile during Bertha (black line) compared with annual profile (grey line)

Fig. 10 Averaged anomaly profiles for the 7 cases during Hondo (bold black line), refractivity (grey line), temperature from COSMIC (dashed line).

Fig. 11 Averaged bending angle anomaly profile for the 7 cases during Hondo (black line) above $12 \mathrm{~km}+/$ - the standard deviation of the mean (grey lines).

Fig. 12 Averaged temperature profile during Hondo (black line) compared with annual profile (grey line).

Fig. 13 Averaged bending angle anomaly profile for 104 TC cases in 2008 (black line) +/- with the standard deviation of the mean (grey lines).

Fig.14 Distribution of positive anomalies between 14 and $18 \mathrm{~km}$ during TCs in 2008. Yaxis shows the number of samples overpassing the anomaly amplitude threshold reported on the $\mathrm{x}$-axis.

Tab. 1 COSMIC ROs during Bertha 2008

Tab. 2 COSMIC ROs during Hondo 2008 


\begin{tabular}{|l|l|l|l|}
\hline $\begin{array}{l}\text { TC } \\
(\mathrm{dd} / \mathrm{mm} \text { hh.min })\end{array}$ & $\begin{array}{l}\text { COSMIC } \\
(\mathrm{dd} / \mathrm{mm} \text { hh.min })\end{array}$ & $\begin{array}{l}\text { Delay } \\
(\mathrm{min})\end{array}$ & $\begin{array}{l}\text { Distance } \\
(\mathrm{km})\end{array}$ \\
\hline $08 / 0703.00$ & $08 / 0702.01$ & -59 & 117 \\
\hline $08 / 0715.00$ & $08 / 0714.19$ & -41 & 71 \\
\hline $10 / 0706.00$ & $10 / 0705.34$ & -26 & 163 \\
\hline $10 / 0706.00$ & $10 / 0704.36$ & -84 & 166 \\
\hline $12 / 0712.00$ & $12 / 0712.37$ & +37 & 181 \\
\hline $12 / 0712.00$ & $12 / 0712.47$ & +47 & 198 \\
\hline $18 / 0703.00$ & $18 / 0702.44$ & -16 & 120 \\
\hline $19 / 0703.00$ & $19 / 0702.07$ & -53 & 137 \\
\hline
\end{tabular}

Table 1

\begin{tabular}{|l|l|l|l|}
\hline $\begin{array}{l}\text { TC } \\
(\mathrm{dd} / \mathrm{mm} \text { hh.min })\end{array}$ & $\begin{array}{l}\text { COSMIC } \\
(\mathrm{dd} / \mathrm{mm} \text { hh.min })\end{array}$ & $\begin{array}{l}\text { Delay } \\
(\mathrm{min})\end{array}$ & $\begin{array}{l}\text { Distance } \\
(\mathrm{km})\end{array}$ \\
\hline $05 / 0200.00$ & $05 / 0200.00$ & 0 & 176 \\
\hline $13 / 0200.00$ & $12 / 0221.59$ & -121 & 163 \\
\hline $18 / 0200.00$ & $17 / 0221.35$ & -145 & 162 \\
\hline $26 / 0218.00$ & $26 / 0220.54$ & +174 & 103 \\
\hline $27 / 0212.00$ & $27 / 0209.47$ & -133 & 126 \\
\hline $28 / 0218.00$ & $28 / 0216.50$ & -70 & 179 \\
\hline $29 / 0200.00$ & $28 / 0221.37$ & +143 & 178 \\
\hline
\end{tabular}

Table 2 


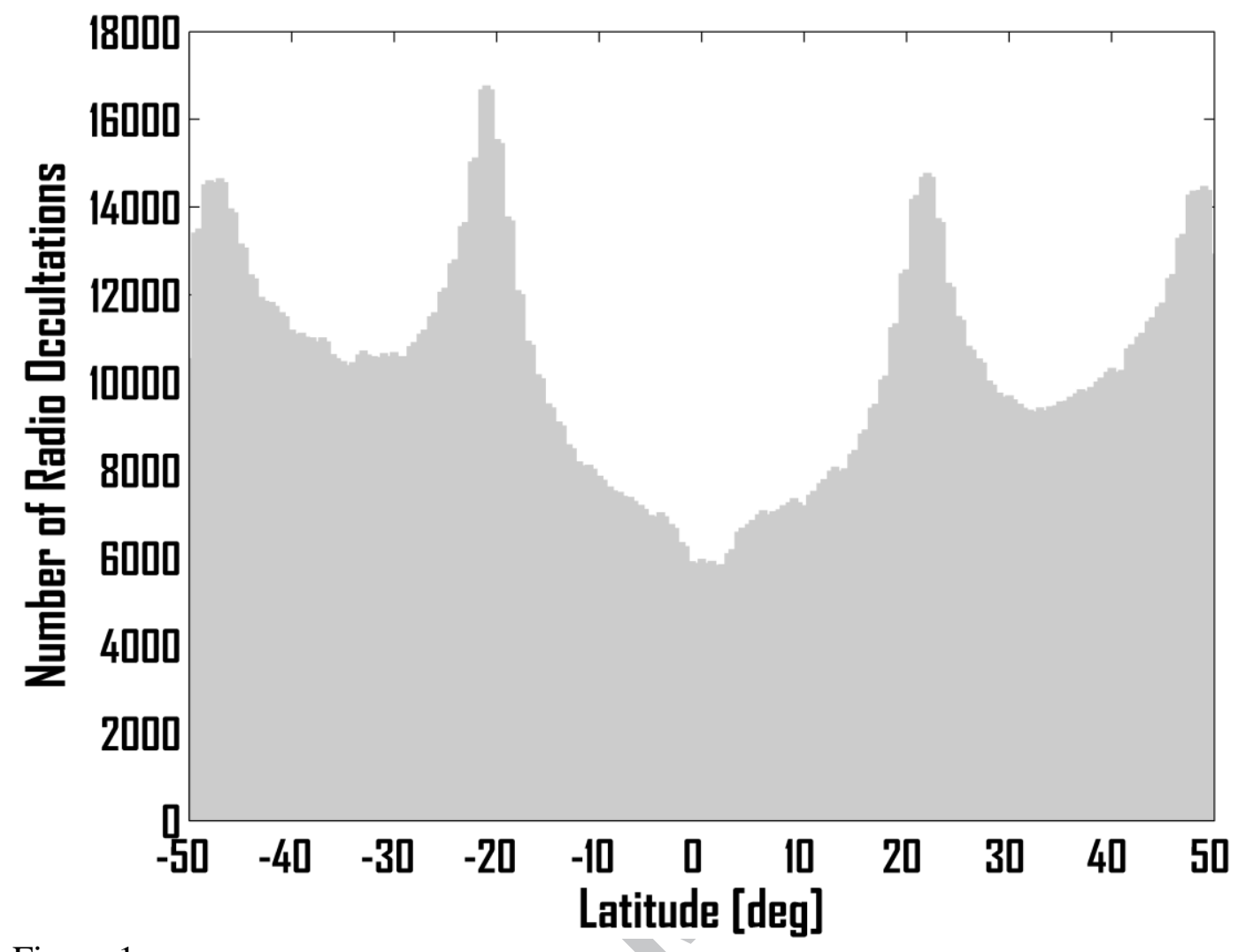

Figure 1

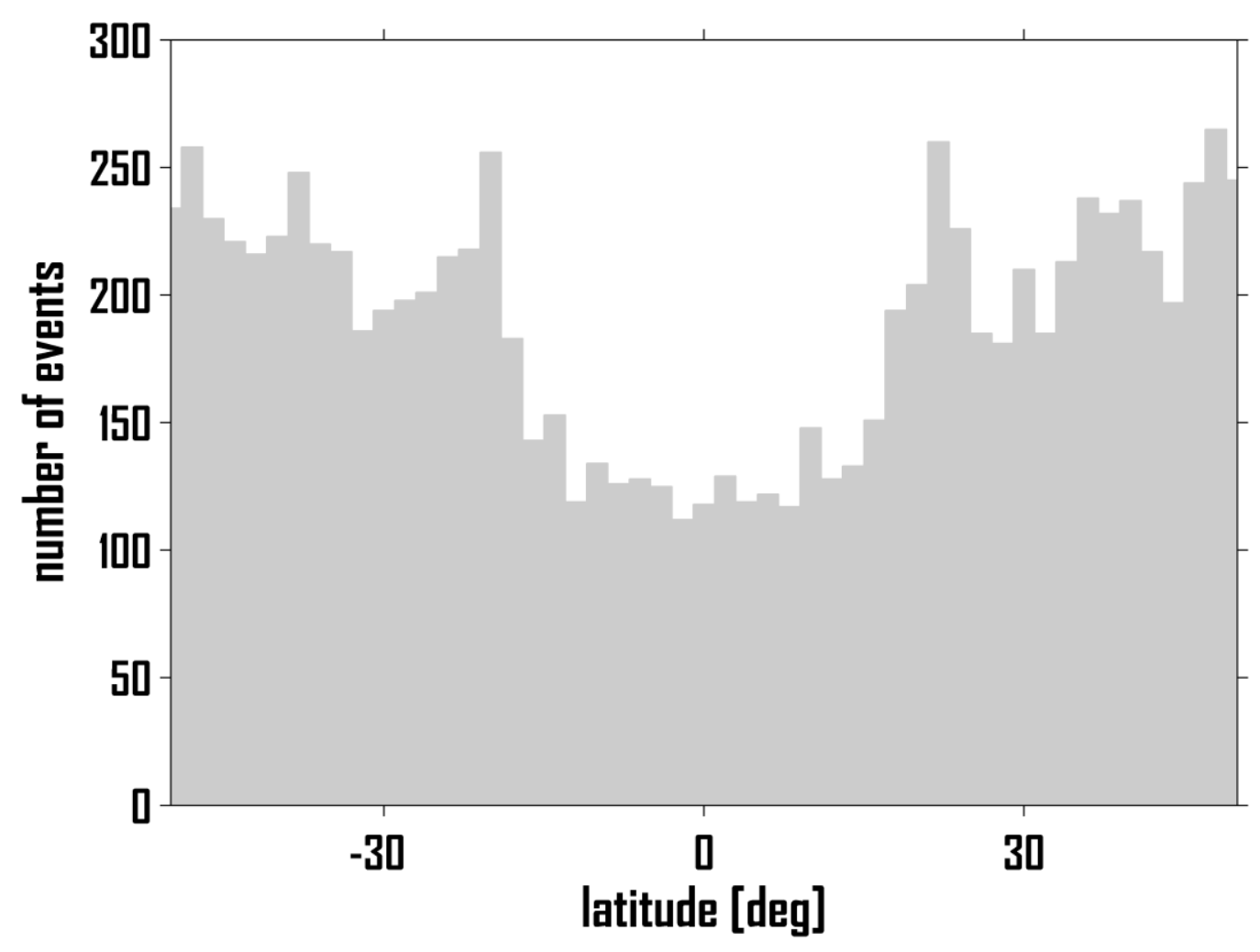




\section{ACCEPTED MANUSCRIPT}

Figure 2

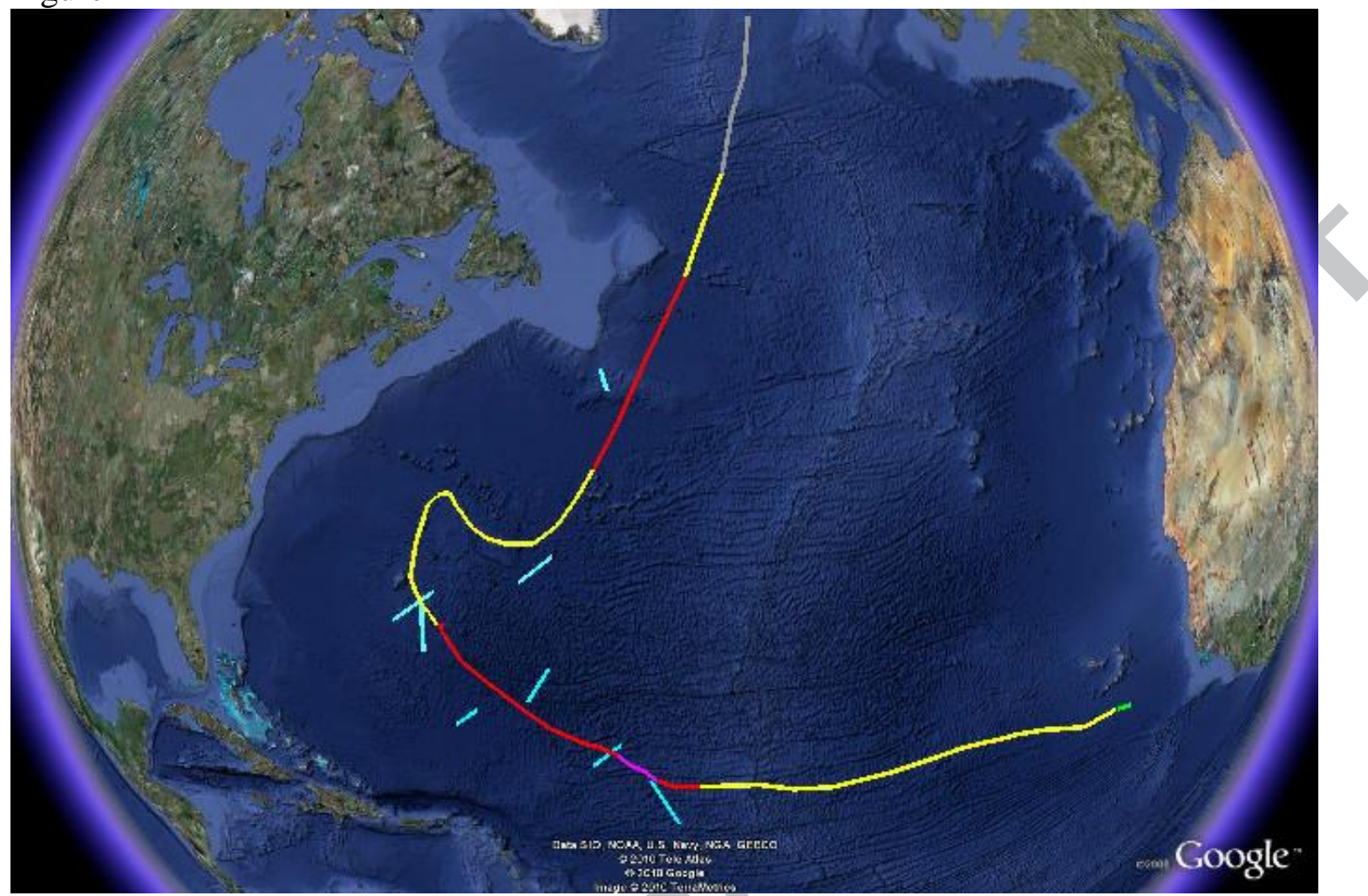

Figure 3

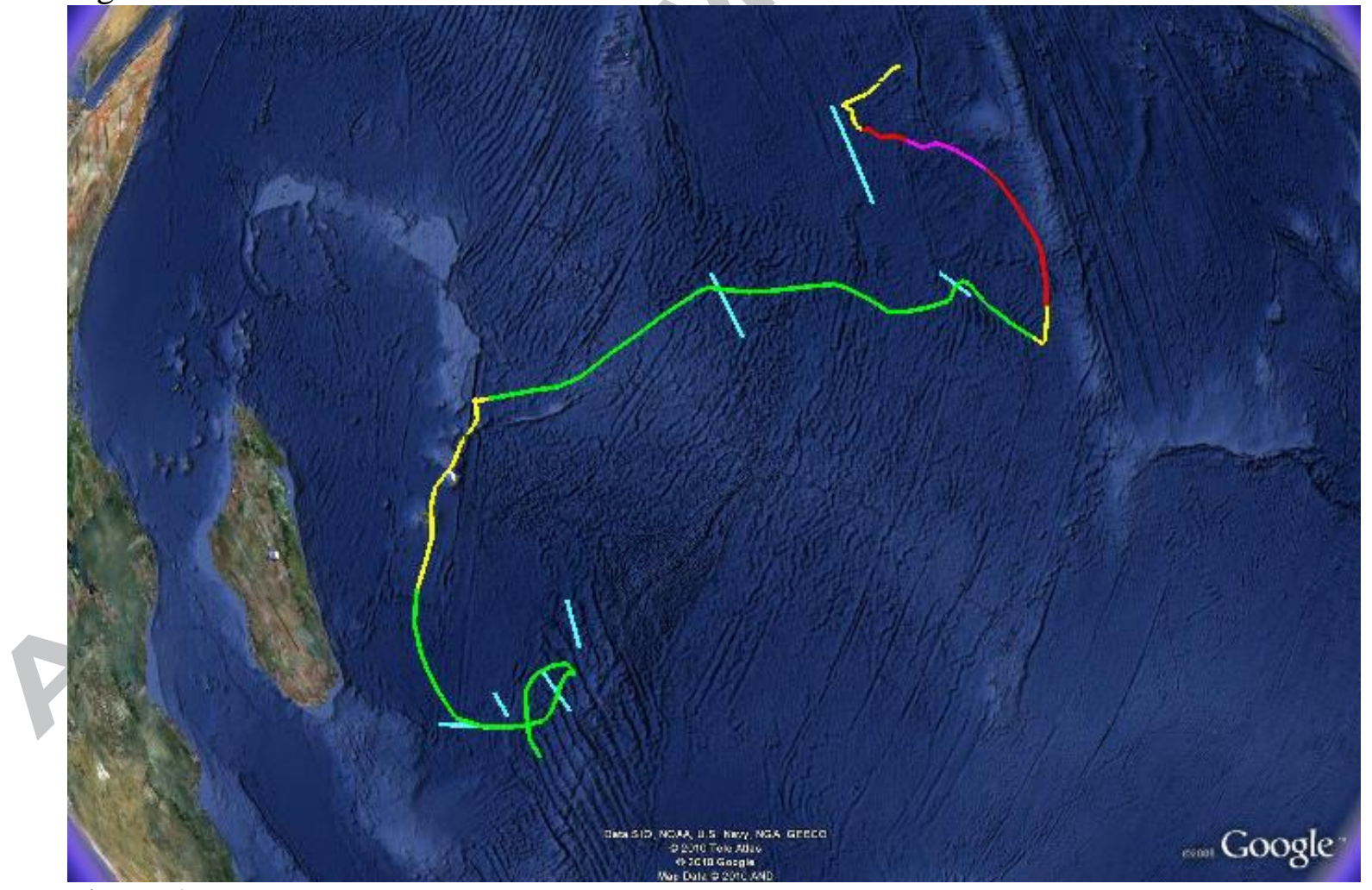

Figure 4 


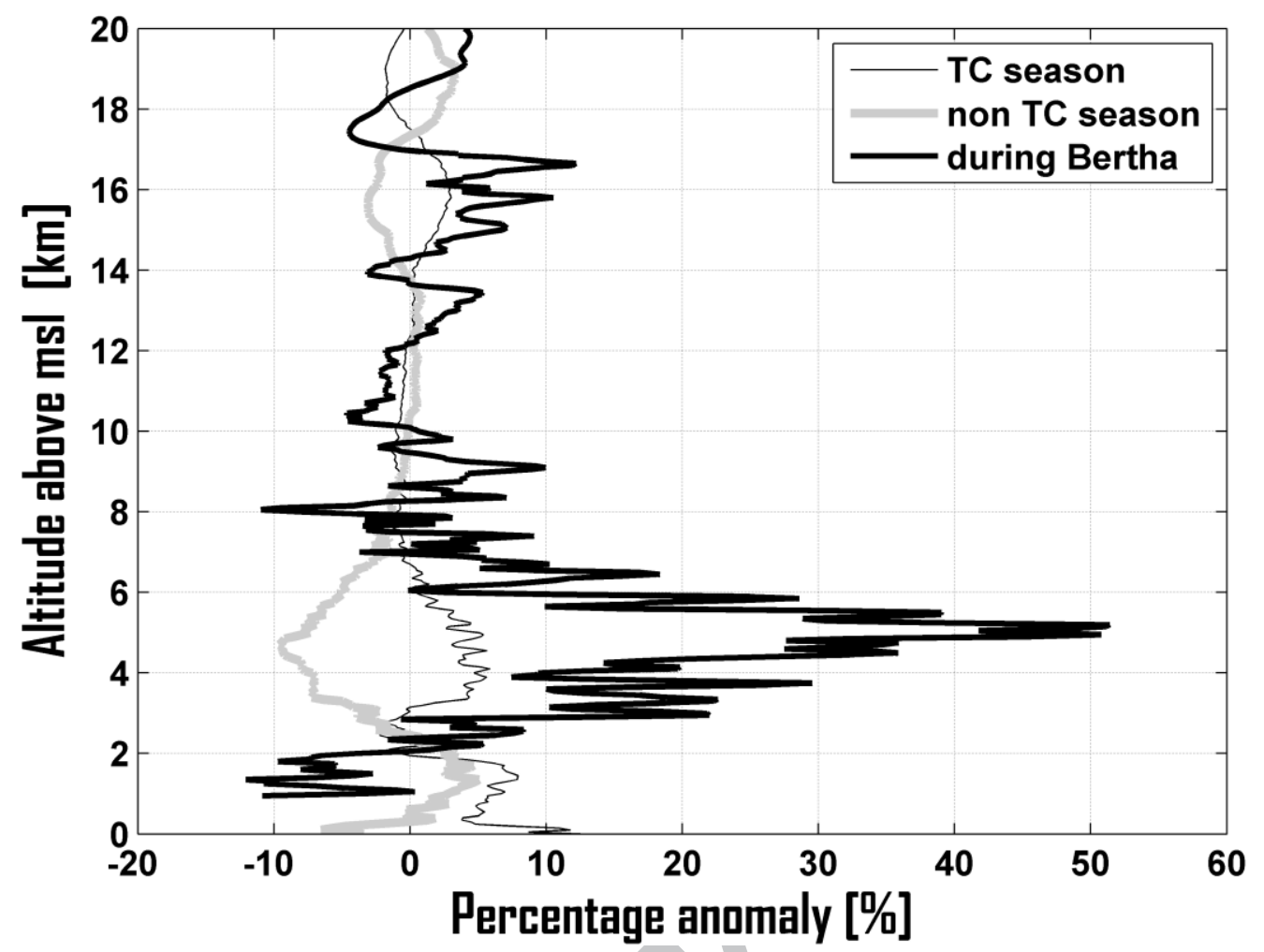

Figure 5

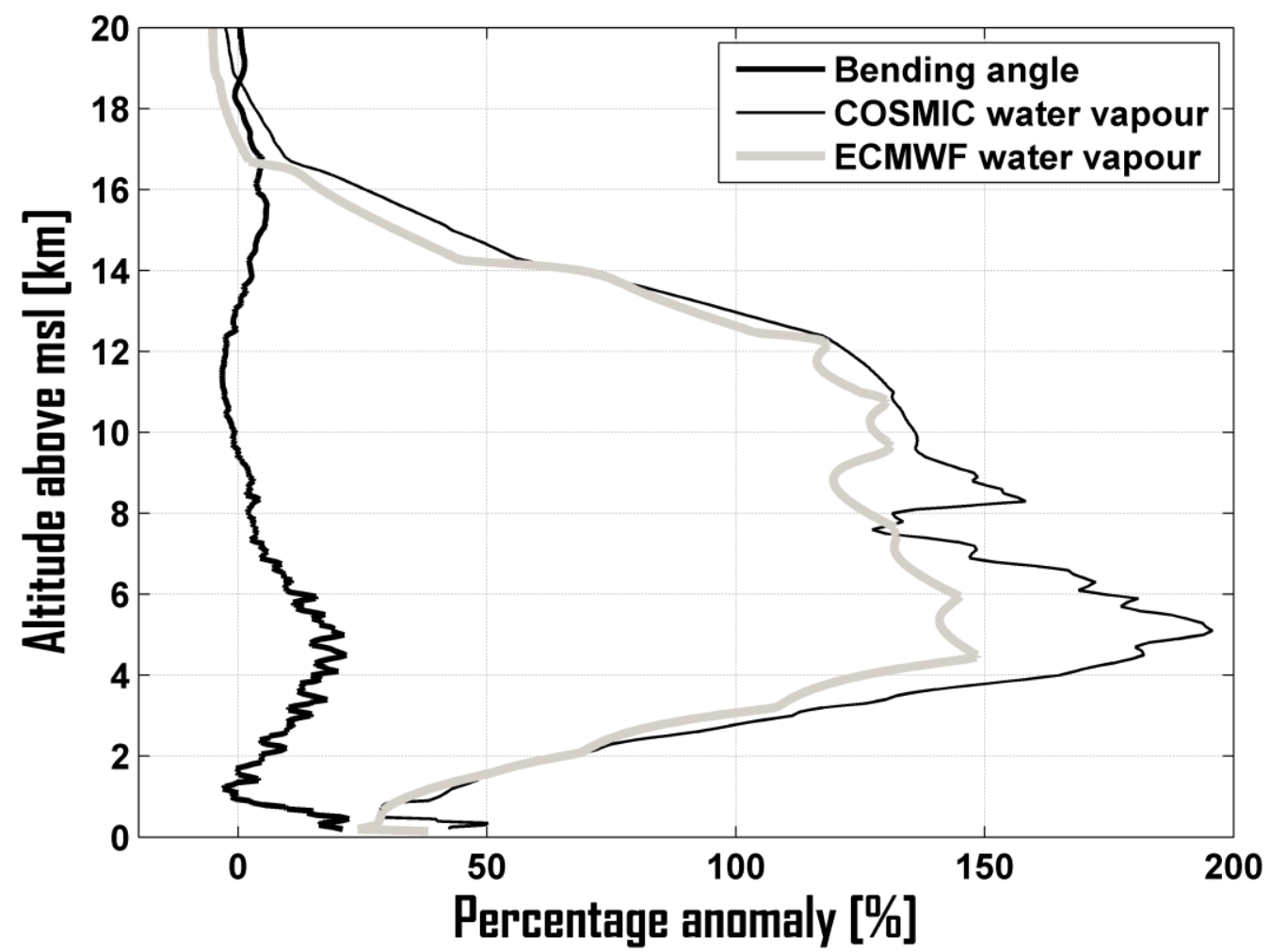

Figure 6 


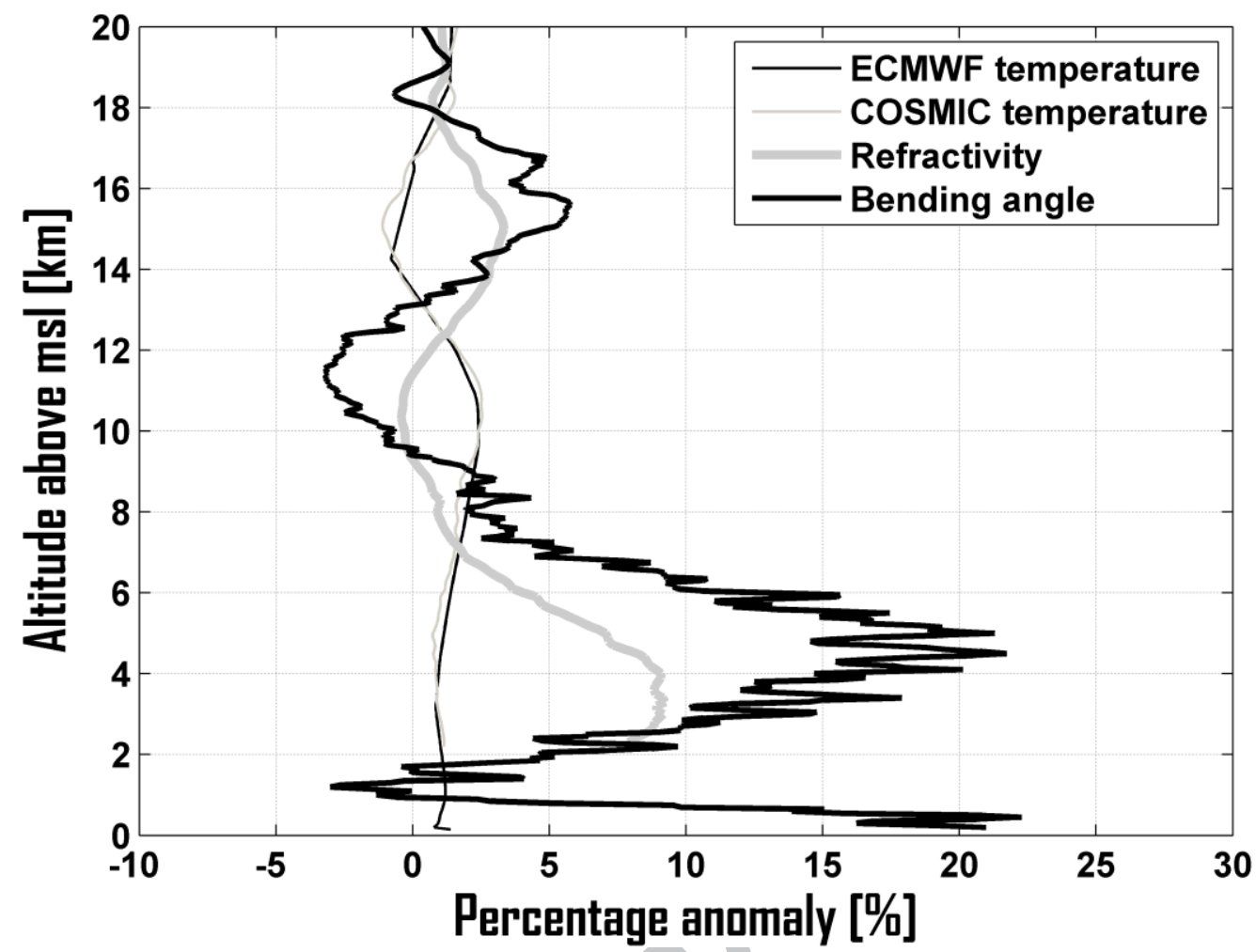

Figure 7

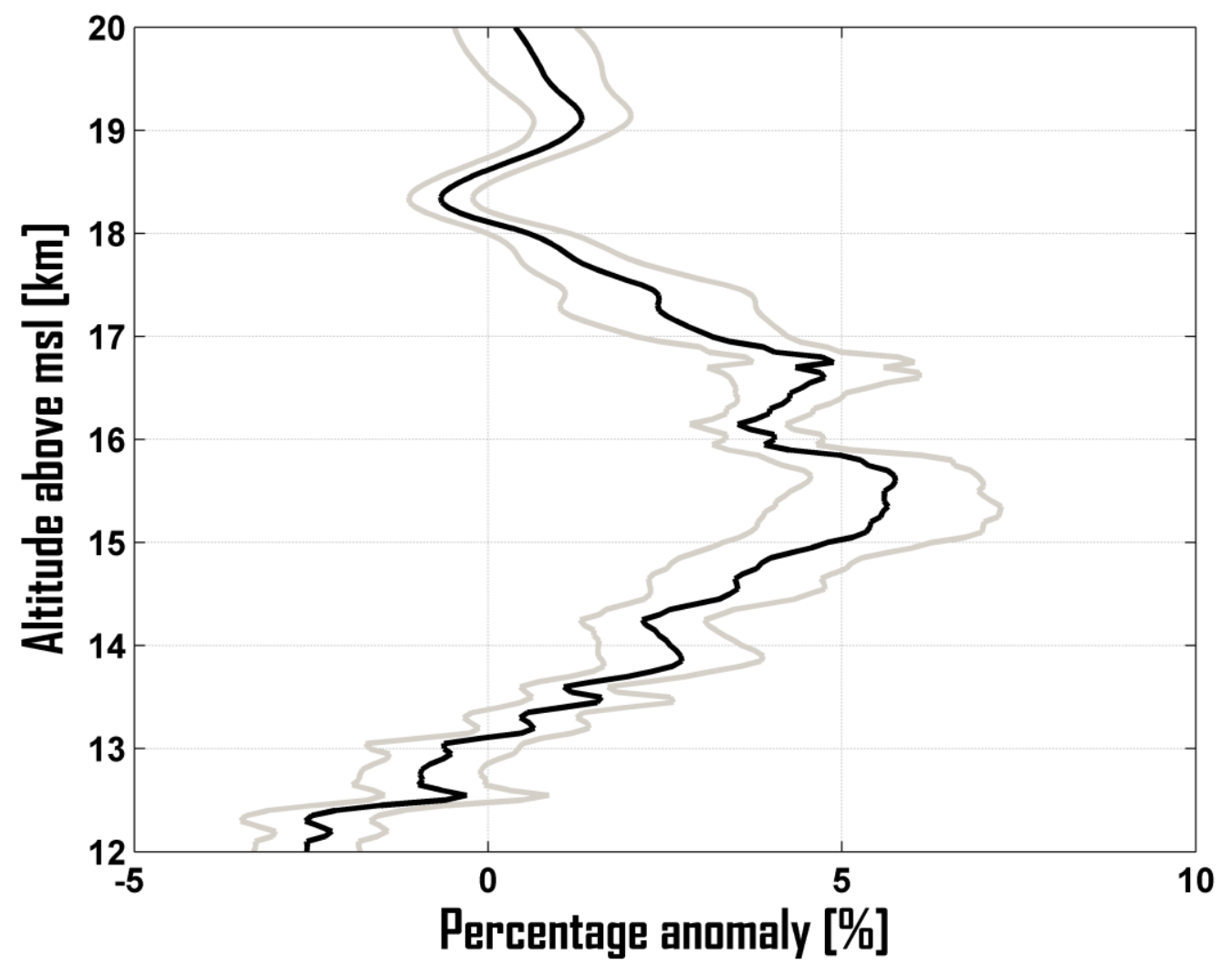

Figure 8 


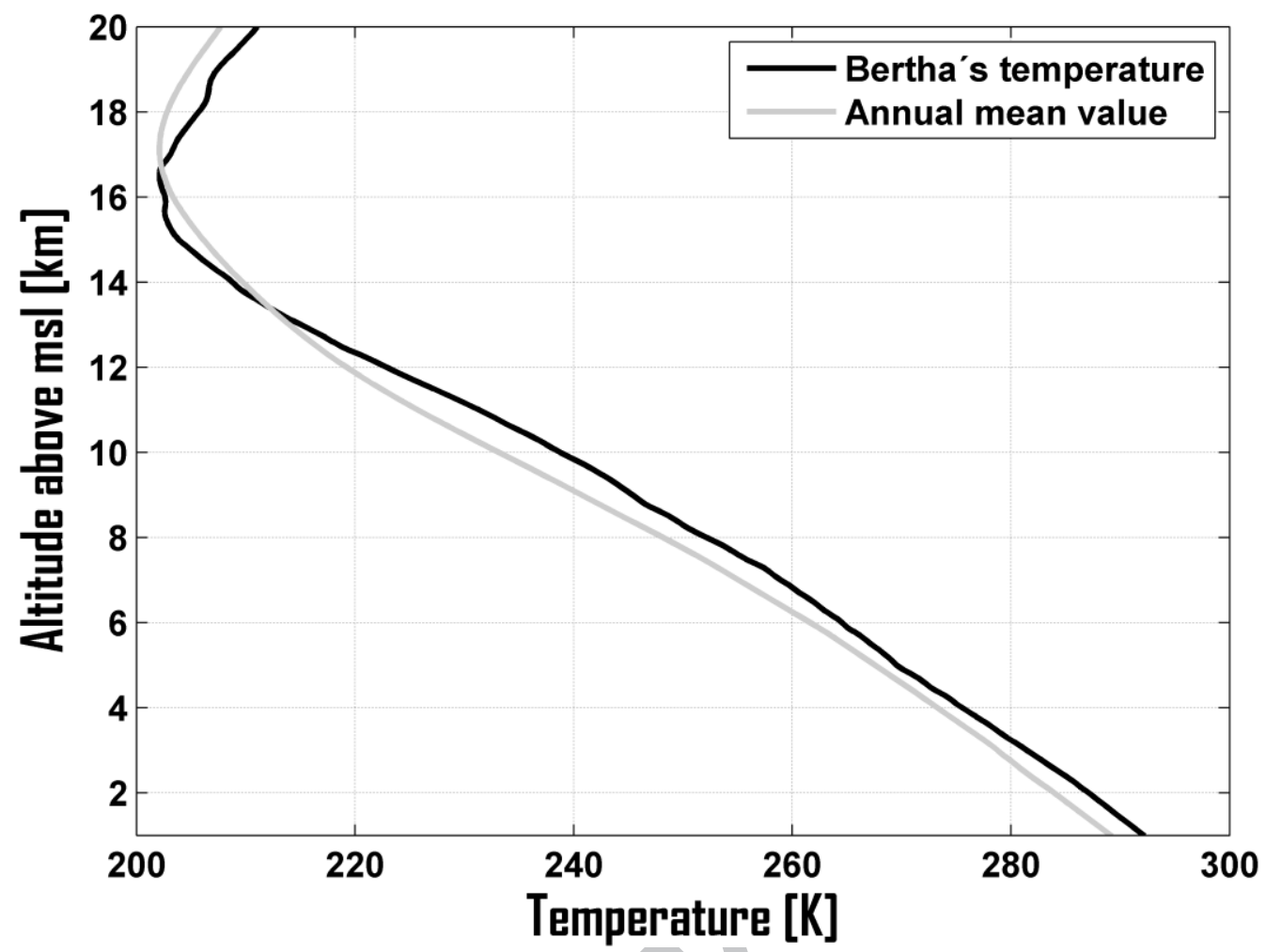

Figure 9

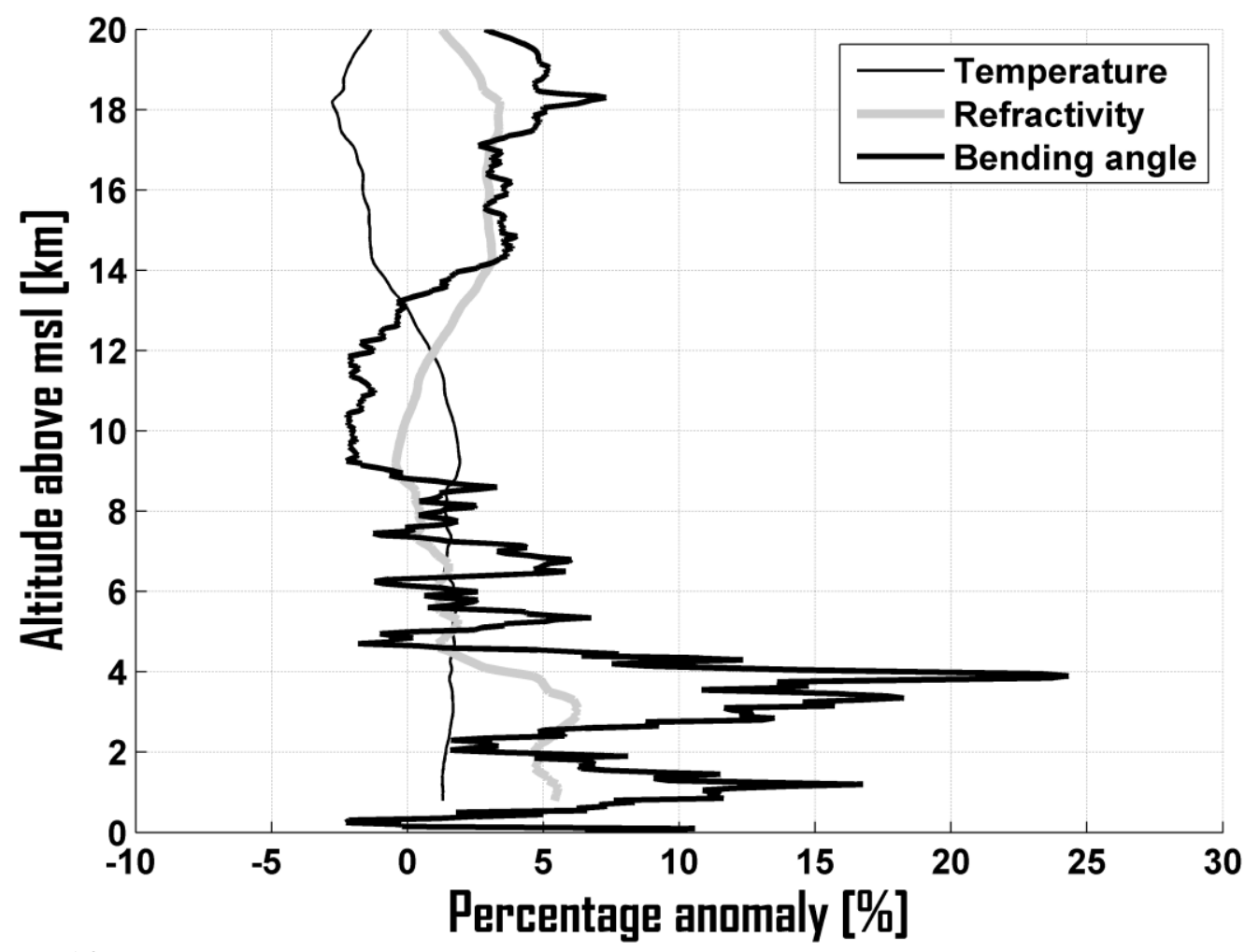

Figure 10 


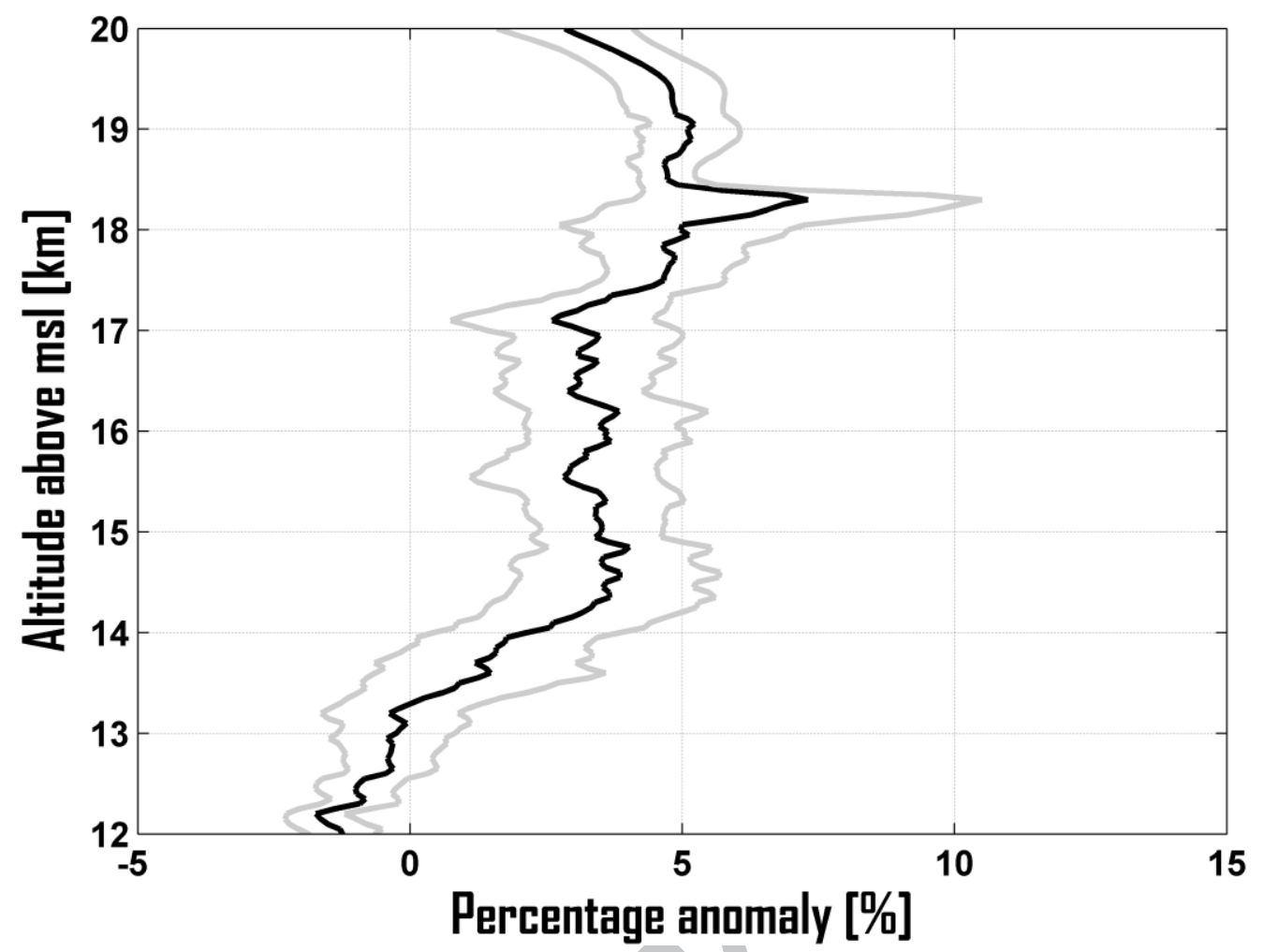

Figure 11

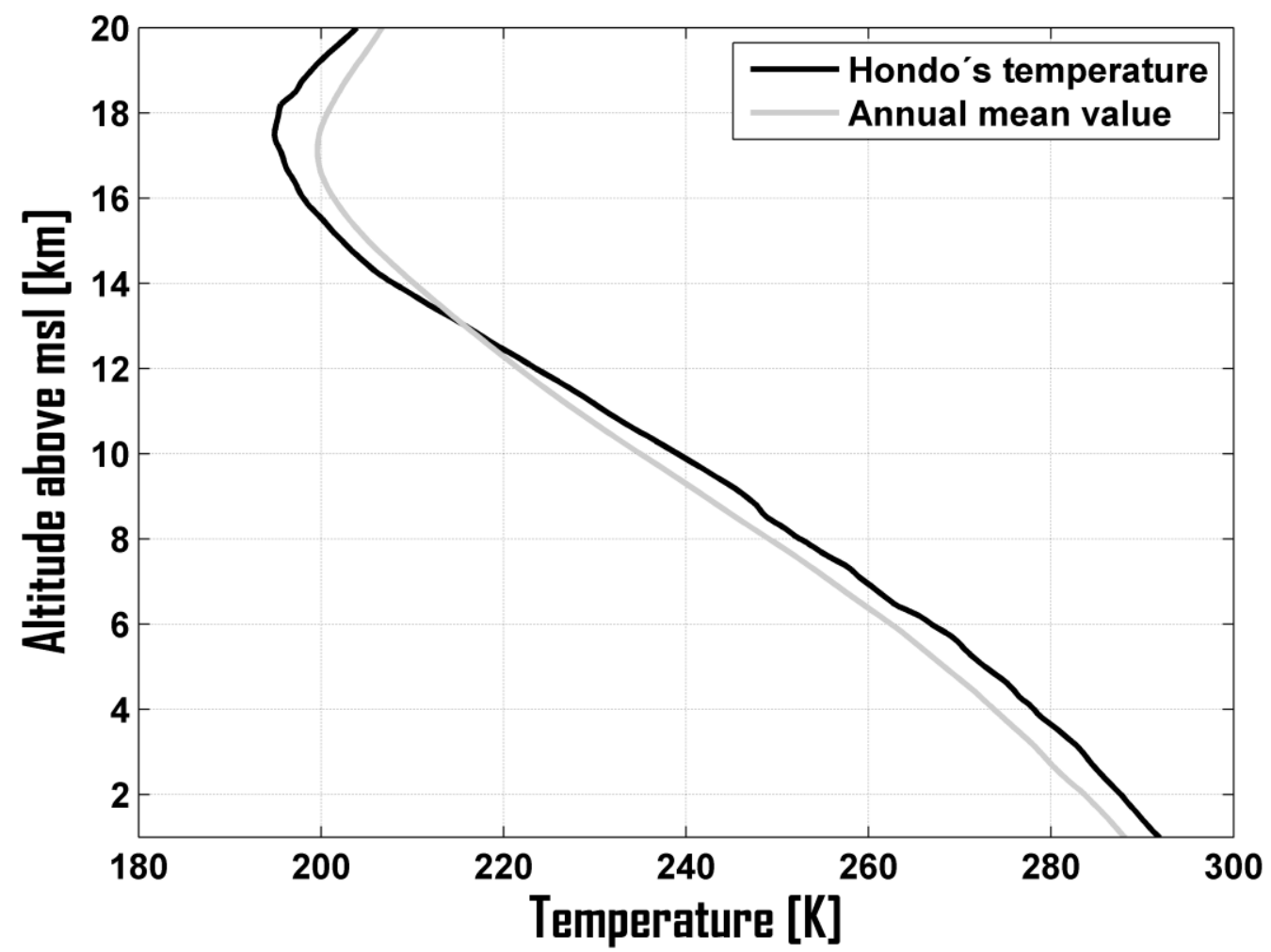

Figure 12 


\section{ACCEPTED MANUSCRIPT}

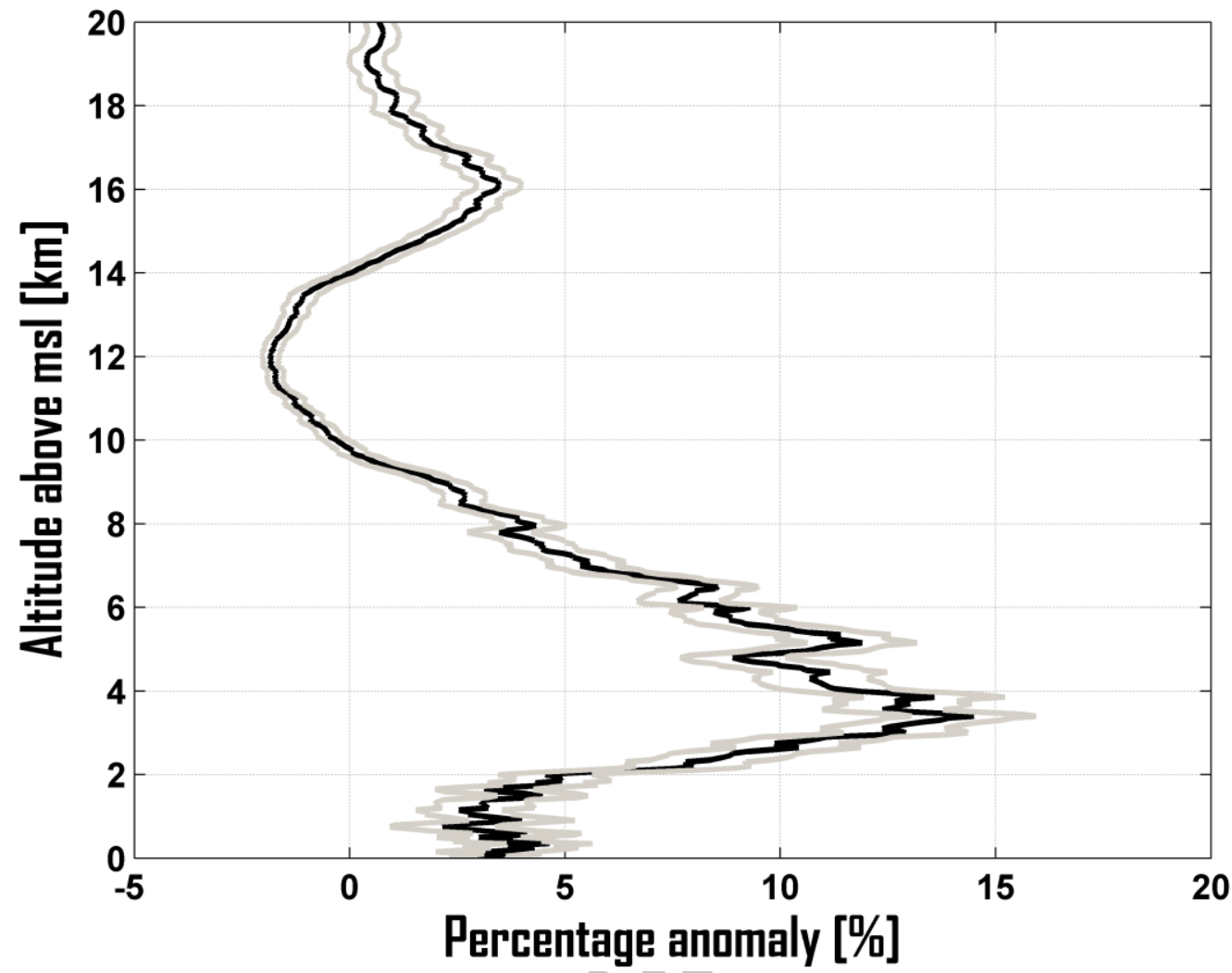

Figure 13

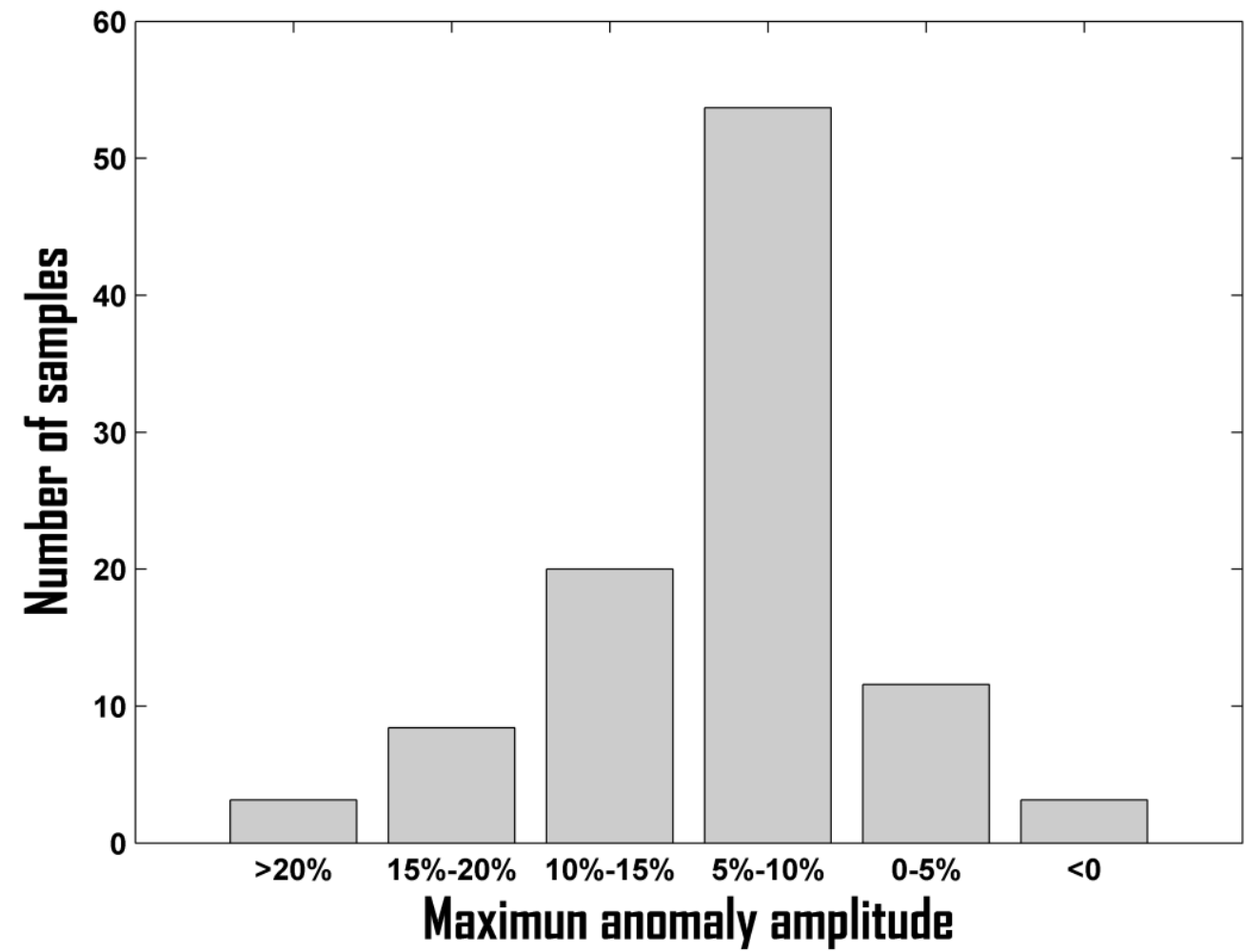

Figure 14 